\title{
The integrated management of water crises: the case for long-range hydraulic interconnections
}

\begin{abstract}
In the last decades the increasingly severity of extreme weather events, whose higher frequency of occurrence is due to climate changes, is heavily affecting our society. The greater intensity of floods, which causes every year catastrophic impacts for lives and human activities, is making the hydro-geological risk higher and higher in many areas. For this reason in many Countries action plans are now deemed urgent and necessary to mitigate the vulnerability of the territory and increase the resilience to adverse impacts.

In Italy a pre-feasibility study concerning the construction of a long-range interconnection system, based on the communicating vessels principle, was carried out. Such a system, connecting existing or new reservoirs through tunnels, could fulfil several functions, playing a key role towards a sustainable management of water resources and a green economy. Being the hydraulic resources in mutual communication, the peak flood discharges of those areas affected by localized and intense rainfalls may be freely redistributed through the entire system, mitigating the hydro-geologic disasters; at the same time, the surplus inflows of rainy seasons may be stored to times of drought. The energy production and storage capacity will be increased, and a multiple use of water resources will be facilitated.
\end{abstract}

\author{
Volume 2 Issue I - 2018
}

\author{
Michele Fanelli,' Guido Mazza, ${ }^{3}$ Antonella \\ Frigerio $^{2}$ \\ 'Consultant, Ricerca sul Sistema Energetico-RSE S.p.A, Italy \\ ${ }^{2}$ Project Manager at Ricerca sul Sistema Energetico-RSE S.p.A, \\ Italy \\ ${ }^{3}$ Executive at Ricerca sul Sistema Energetico-RSE S.p.A, Italy
}

Correspondence: Michele Fanelli, Consultant, Ricerca sul Sistema Energetico-RSE S.p.A, Italy, Email michele3I fanelli@gmail.com

Received: December 05, 2017 | Published: February 07, 2018

\section{Introduction}

The water resources management is assuming world-wide a critical role in the general framework of the competition in the use of fresh water and keeping into account the effects due to the climate change. This task is gaining criticality not only for developing countries but more and more even for the industrialised ones. Among the several possibilities offered by the present technologies, the longrange interconnection infrastructural systems may be considered an effective solution. In the following, a short remind of past and present worthy examples of interconnection projects all around the world is presented. Afterwards, the focus will be addressed to the Italian case; having in mind the recent extreme climatic events occurred in Italy, the hydro-geological hazards management is demanding a quite pressing response for devising cost-effective means of damage prevention and mitigation in the frame of risk assessment. At the same time this effort will play a key role towards sustainable management of water resources and the raise of green economy taking in mind that a multiple use of water and the increase of green energy production should be promoted according to the present socio-economic, environmental and energy European policies.

\section{Past and present examples of interconnection projects}

Since the early cultures great endeavours to control and divert the flow of water to supply the place of demand were spent. In Egypt some prehistoric irrigation works that exploited the floods of the Nile River for irrigation still exist. In Mesopotamia some embankments of the abandoned canals built by the Sumerians to use the water of the Tigris and Euphrates Rivers for irrigation are still present. The principle of local water transfer by means of communicating pipes was well known since the $2^{\text {nd }}$ millennium BC: e.g. in the city of Mycenae, the underground cistern is an impressive engineering feat that allowed the citadel unlimited and secure water supply; the Hiskia tunnel was built to bring water from the Gihon Spring to the Pool of Siloam, inside the City of David, the original site of Jerusalem. In the same epoch other evidences of hydro-technical structures exist. In the early $1^{\text {st }}$ millennium $\mathrm{BC}$, in Iran the Persian developed and spread throughout their entire empire the qanāt technology: through a series of gently sloping underground tunnels, often several kilometres long, the groundwater flows downhill from an aquifer or water well to surface for irrigation and domestic use. A water delivery system is also present in the island of Samos where the Eupalinos aqueduct supplied the ancient capital with fresh water. The technique for aqueducts was further improved in the Classical and Hellenistic times when pipelines were no more protected by costly tunnels. Moreover, pressurised pipelines started appearing as the one documented in Pergamum. ${ }^{1-5}$ In general conduits were installed underground to hide them from enemies during sieges. Anyway, Etruscans started building channels for irrigation and water supply, and subsequently this technology spread over the whole Roman empire, particularly during the long period of the Pax Romana. In fact, only at the end of the Third Punic War, Romans dared to build a channel with a structure above surface, the Aqua Marcia aqueduct, the first of this type (Figure 1).

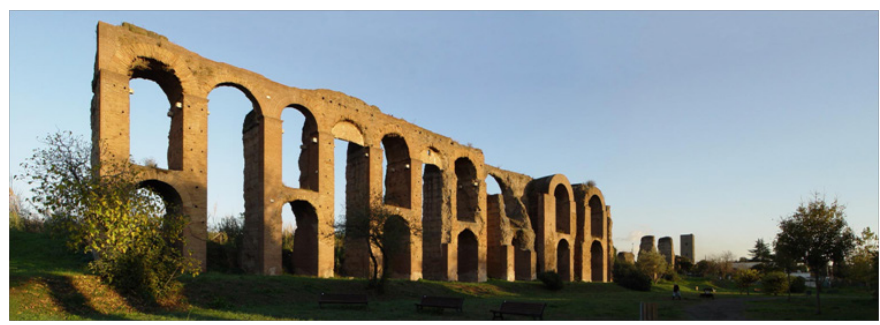

Figure I The Aqua Marcia aqueduct that supplied the ancient Rome.

The water provided by Romans aqueducts was really important for the expansion of Rome as a large imperial city. Moreover, the 
bridges of Roman aqueducts are commonly considered as a worthy example of combined beauty, functionality and engineering skill. Nowadays, interconnected tunnels and canals still fulfil the function of transferring natural hydraulic inflows from regions of above average precipitations - or from regions endowed with other water sources, for instance fossil underground reserves - to arid or semi-arid zones. In Italy meaningful examples of large interconnection projects were already built at the end of XIX - beginning of XX century (Figure
2)(Figure 3). These examples of water transfer however have often given rise to conflicts due to the opposition for the sharing of water resources. In the last decades, the central planning Authorities of some countries, e.g. Libya, Brazil, France, Spain, China and others (Figure 4)(Figure 5),(Table 1) have promoted the design and building of complex systems of long-range hydraulic conduits, integrated by reservoirs and pumping stations where required by the land relief of the respective countries.

Table I Long-range interconnection schemes in the world. ${ }^{10}$

\begin{tabular}{|c|c|c|c|c|c|}
\hline $\begin{array}{l}\text { Scheme } \\
\mathbf{N}^{\circ}\end{array}$ & Country & $\begin{array}{l}\mathbf{N}^{\circ} \text { of schemes } \\
\text { completed }\end{array}$ & $\begin{array}{l}N^{\circ} \text { of schemes } \\
\text { proposed }\end{array}$ & $\begin{array}{l}\text { Annual transfer, bcm } \\
\text { completed }\end{array}$ & $\begin{array}{l}\text { Annual } \\
\text { transfer, bcm } \\
\text { proposed }\end{array}$ \\
\hline I & Morocco & 1 & - & 1.51 & - \\
\hline 2 & South Africa & 24 & - & 2.51 & - \\
\hline 3 & Sudan & 1 & & 7.3 & \\
\hline \multicolumn{2}{|c|}{ Total for Africa } & 26 & & 11.32 & - \\
\hline 4 & Bolivia & - & 1 & - & 0.2 \\
\hline 5 & Brazil & - & 1 & - & 1.5 \\
\hline 6 & Canada & 38 & 10 & 262.46 & 463.6 \\
\hline 7 & Chile & 2 & - & 3.15 & - \\
\hline 8 & U.S.A. & 19 & 7 & 37.56 & 381.6 \\
\hline \multicolumn{2}{|c|}{ Total for Americas } & 59 & 19 & 303.17 & 846.9 \\
\hline 9 & Australia & 1 & - & 1.13 & - \\
\hline 10 & China & - & 3 & - & 44.8 \\
\hline II & India & 6 & - & 28.85 & - \\
\hline 12 & Iraq & 6 & - & 15.8 & - \\
\hline 13 & Japan & 1 & - & N.A. & - \\
\hline 14 & Malaysia & - & 1 & - & 0.14 \\
\hline 15 & Pakistan & 8 & - & 99.95 & \\
\hline \multicolumn{2}{|c|}{ Total for Asia } & 22 & 4 & 145.73 & 44.94 \\
\hline 16 & Czech Rep. & 4 & 2 & 15.15 & 2.2 \\
\hline 17 & Finland & I & & 0.09 & \\
\hline 18 & France & 5 & - & 2.35 & - \\
\hline 19 & Germany & 2 & - & 0.47 & - \\
\hline 20 & Portugal & 1 & - & 0.01 & N.A. \\
\hline 21 & Romania & 3 & N.A. & N.A. & N.A. \\
\hline 22 & $\begin{array}{l}\text { Russia \& } \\
\text { C.A }\end{array}$ & 5 & 2 & 60 & 47 \\
\hline 23 & Spain & 3 & 1 & 1.3 & 1 \\
\hline \multicolumn{2}{|c|}{ Total for Europe } & 24 & 5 & 79.37 & 50.2 \\
\hline \multicolumn{2}{|c|}{ Grand Total } & $|3|$ & 28 & 539.59 & 942.04 \\
\hline
\end{tabular}

BCM, Billion of $\mathrm{m}^{3}$; N.A., Not available 


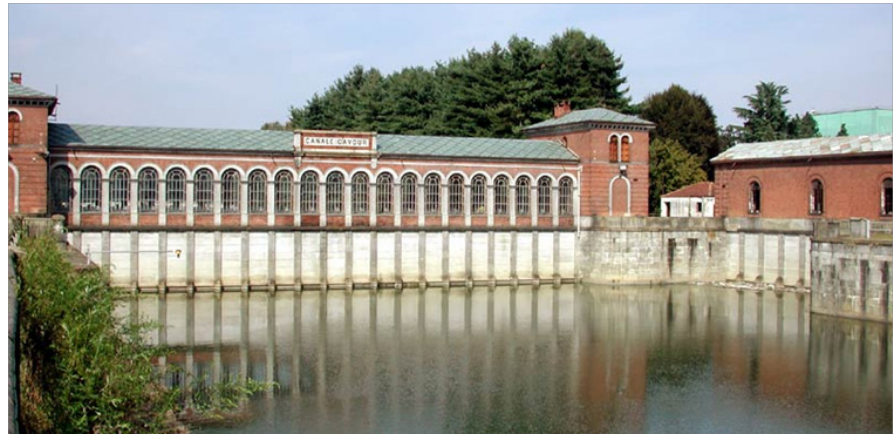

Figure 2 The Cavour open channel, Piedmont (Italy), built in I863.

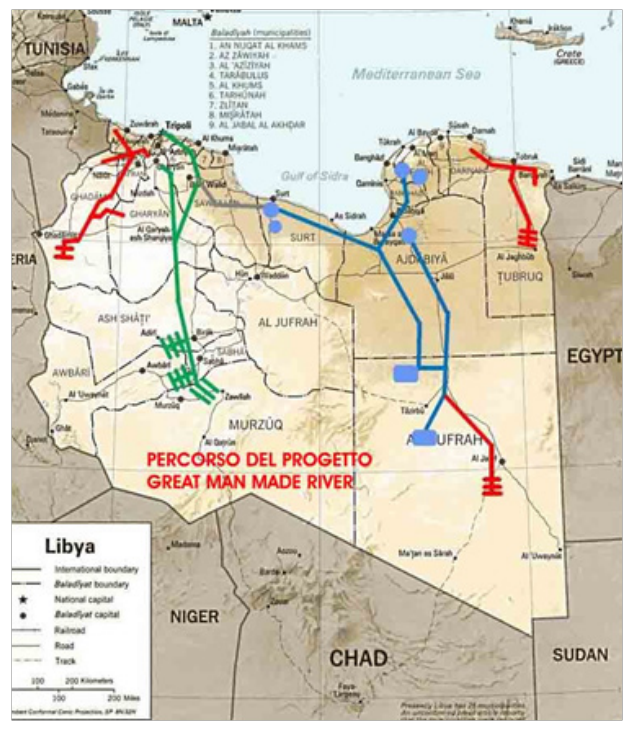

Figure 4 The Great Man-made River Project in Libya connecting the underground fossil water reserves to the populated areas of the Mediterranean Sea (left) and long-range water transfer system in Brazil connecting the São Francisco River with the arid interior regions (right).

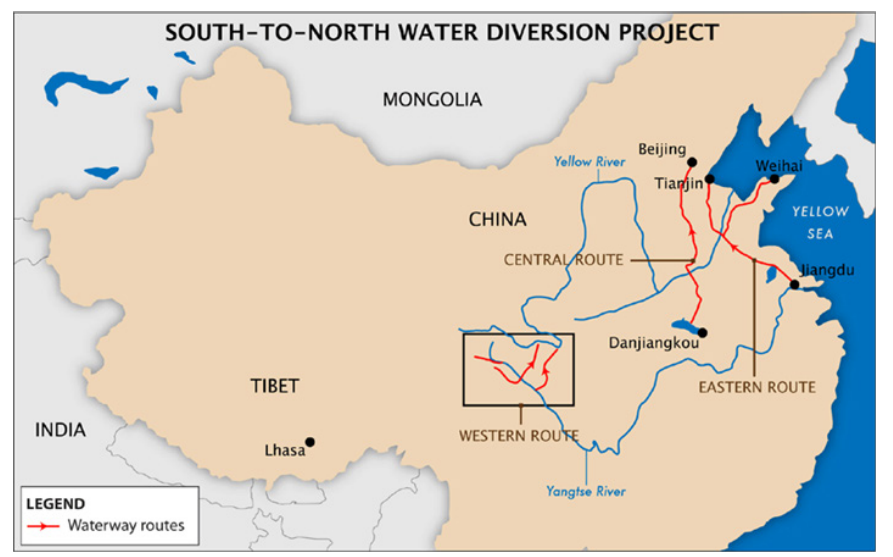

Figure 5 The long-range water transfer system in China connecting the central areas of the Country to the semi-arid areas of the North.

\section{The concept of a large-scale hydraulic interconnection in Italy}

Differently from the cases shortly reminded above, the basic ideas of the system here presented do not merely consider the water transfer from one watershed to a more or less closer one. As
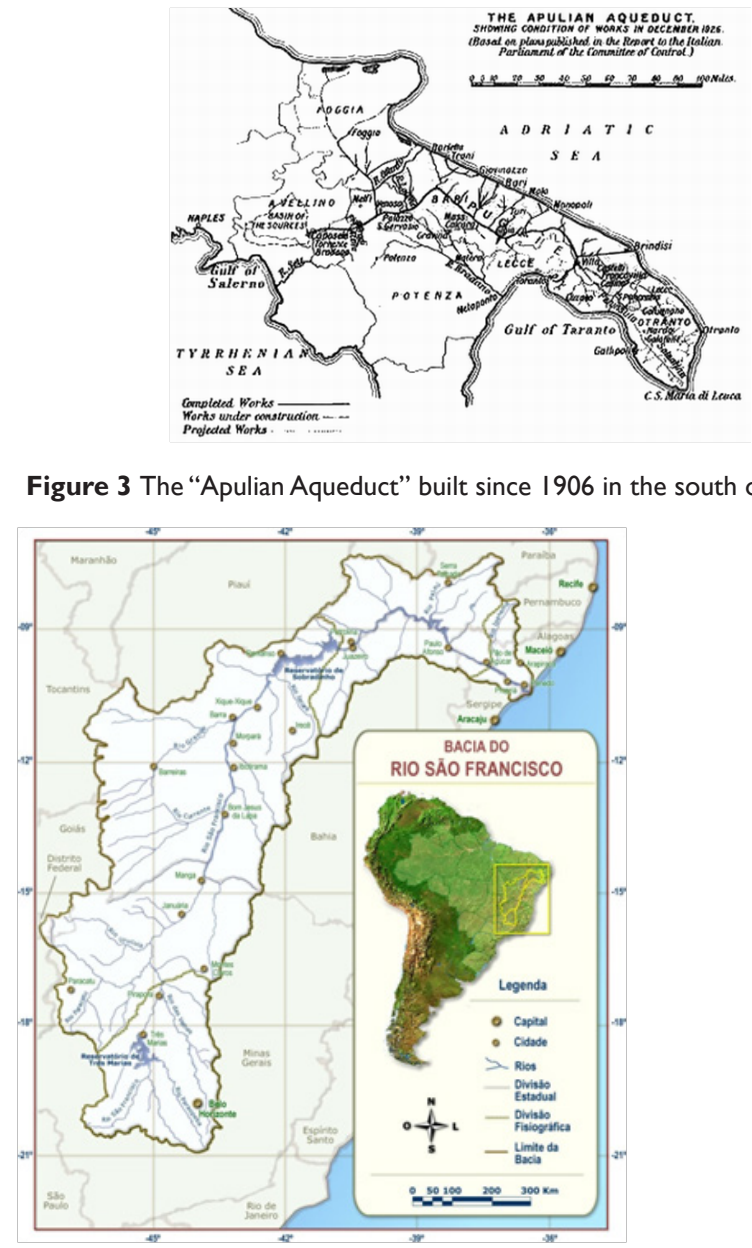

a matter of fact, the overall capacity of the reservoirs, to be created through the erection of dams, fulfils the function of transferring the surplus inflows of rainy seasons to the times of drought. The stored volumes avoid at the same time most of the more damaging floods. An added benefit would be the production of additional hydroelectric energy, provided the interconnected system is situated at a suitable elevation. The technical and economic feasibility of such systems, many hundreds of kilometres long (up to more than 1,000 km) and costing in the range of some tens of billions of euros, is just now becoming conceivable, in the face of the growing value attributed to the resource "water" - and of the increasing economic losses due to hydrological events - on one hand, and of the advancing technology of large infrastructure building on the other hand. In Italy, the Authors of the present paper have undertaken preliminary steps in order to carry out a pre-feasibility study concerning the possibility of creating a system of reservoirs connected by tunnels and distributed along the Apennines mountain range that runs all through the NW-SE axis of the Italian peninsula. Such a system, more than $1,000 \mathrm{~km}$ long and comprising about 60 small or medium-sized reservoirs for a total capacity of nearly $2,000 \mathrm{Mm}^{3}$, would catch primarily the peak flood discharges of the Northern rivers, which cause annually very grievous floods and landslides, and transfer significant volumes of water to the Southern regions, which statistically undergo severe summer droughts. The distributed storage capacity of the system would also 
alleviate the hydro-geologic disasters recurring during autumn or winter in the geologically unstable Southern territories as well as in some of the Northern regions (Figure 6). The initial conception of this system ${ }^{6,7}$ assumes that all reservoirs and interconnecting tunnels would be situated at the same altitude (tentatively at around $500 \mathrm{~m}$ above sea level), thus creating a network of freely communicating vessels dispensing with the necessity either of pumping stations or of regulating gates, in favour of the maximum simplicity of functioning and management of the system. Of course, in every study of this kind an in-depth, exhaustive analysis of the cost and benefit balance of the enterprise has to be carried out in parallel with the optimisation of layout as well as the appraisal of technical feasibility and of the options for financial planning. The huge capital layout required should be distributed over a span of many years and in this way the yearly allocations would be of the same order of magnitude as the economic losses now incurred every year as a consequence of extreme hydro-geological events. The long-range interconnection systems herein considered need be neatly distinguished, in principle as well as in functions, from the changes of river watershed that sometimes were carried out in the past and that proved more often than not to cause harmful environmental side effects. Schematically, while a change in watershed diverts all of the river inflows from its natural course to a different final destination, an interconnection puts the hydraulic resources of different regions in mutual communication so that the surplus of one region may be shared with other regions suffering from a paucity of inflows, without denying to the waterrich one the availability of the useful contributions of the local rivers. Thus no harmful ecological side effects should derive from this kind of infrastructure; indeed, the draining of excessive natural inflows from the more endowed regions could alleviate local problems tied to large floods.

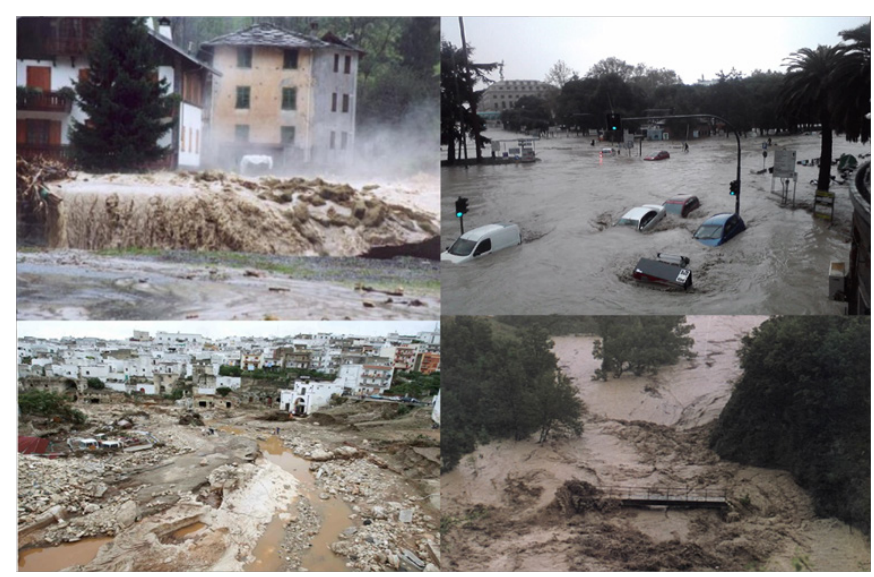

Figure 6 Examples of recent hydro-geological disasters occurred in Italy.

A second important consideration has to be devoted to the question of public opinion reactions. Hence the necessity of a serious effort on the part of the interconnection proponents, in order to demonstrate in effective ways the usefulness (or indeed the necessity, as the case may be) of undertaking the realisation of such systems. A third consideration concerns the difficulties implied by the necessity of large capital outlays over a substantial period of time. The rational assessment is the fact that in the absence of such infrastructures huge sums need either to be set apart to be expended, practically each year, to repair hydro-geological damages, or are lost as 'lost production' brought about by floods or droughts. These expenses would be largely avoided by the coming into service of the interconnection.
Lastly, the physical existence of an interconnection system would not, by itself, magically eliminate the adverse effects of regional and temporal imbalances. Indeed, such a huge, complex system would need to be operated under the governance of a specialised Authority, which should monitor in real time the hydrologic situation, effect real-time projections for the near future (with the help of advanced mathematical models of the system dynamics) and issue the adequate directives to the local operational units. In the last decade, many European countries (not only Italy, but also France, the U.K., Germany and other European countries, not to mention the Far-east regions) have experienced recurring, unusually heavy hydraulic and hydro-geological hazards. These are commonly attributed on one hand to an assumed trend towards climatic change, on the other hand to the demographic expansion and the exponential development of environmental alterations inflicted on the territory by human activities (deforestation, urbanisation, topsoil erosion,...) which make for increasing vulnerability of the socio-economic fabric. ${ }^{8}$ The crises in question pose with ever increasing urgency the problem of revisiting the traditional planning of water cycle management in the socioeconomic context. The hitherto prevailing localistic approach, indeed, shows its limitations as it becomes more and more evident that an integrated, regional or better inter-regional approach should instead be adopted. Only in this way the unbalances in the water availability of different regions - or the consequences of their different vulnerability to extreme hydrologic events - could be redressed. The basic issue to contend with is the recognition that within industrialised countries water is both a primary resource subjected to a rigid demand and a source of hazards; therefore the rational governance of the natural water cycle (including its artificial modulation and re-distribution) make for an essential part of a holistic approach to territorial planning. In this view, the current practice of passively waiting for hydrogeological disasters to occur and only afterwards palliating their consequences with great efforts and expenses appears as utterly irrational. Indeed, the question naturally arises: 'Would a different approach to water management be able to avoid (or strongly mitigate) the occurrence of these hazards in the first place?' It is the contention of the present paper that long-range hydraulic interconnection infrastructures may constitute at least as an option. In the following, the initial stages of the analysis made by the Authors for the Italian peninsula will be shortly illustrated in order to expound the possible advantages of such an approach. As concerns Italy, the perception of a turning point in the worsening of the hydro-geological hazards can be dated roughly in the autumn of 1994, when disastrous floods hit the Piedmont region. Since then severe autumn and winter floods have occurred practically each year, while at the same time damaging summer droughts have struck the Southern half of the peninsula. After the disastrous floods of Florence and Venice of November 1966 (Figure 7) an officially appointed study Commission ${ }^{9}$ issued a Report which analysed the situation and concluded advocating the necessity of building a number of new reservoirs and fluvial expansion zones. This plan was implemented only partially (e.g. with the construction of Bilancino dam for the partial protection of Florence against flooding). The total presumed cost of the overall plan was estimated at about 15 billion euro (at present currency value). The technological progress intervened to date in the construction equipment makes now possible to conceive a somewhat different system, consisting in a complex of reservoirs situated at a uniform elevation and connected by pressure tunnels. The reservoirs would be located along the Apennines mountain range, which runs along the NW-SE central axis of the Italian peninsula for a length of more than $1,000 \mathrm{~km}$. The function of such an interconnected system would be not only to compensate the local time and space 
irregularities in the outflows of the many water courses of the Apennines valleys, but also to store the excess winter discharges of Northern rivers floods and render them available to alleviate the summer droughts of the South. The reservoirs being situated at a uniform elevation, tentatively fixed at $500 \mathrm{~m}$ a.s.l., would avoid the necessity to foresee the construction of pumping stations; besides, the only gates to be installed in the tunnels would be the isolation gates to be operated in case of maintenance works. In this way the system would embody the maximum simplicity and reduce the overall costs. An analysis of the local possibilities has shown that the system could include about 60 medium-sized reservoirs, to be created by new dams not higher than $100 \mathrm{~m}$, for a total storage capacity of about 2 billion $\mathrm{m}^{3}$ (Figure 8). The total length of the connecting tunnels (of $4 \mathrm{~m}$ internal diameter) would amount to about $1,500 \mathrm{~km}$, extending from the Ligurian Apennines in the North to the Calabrian Apennines in the South (Figure 9). The total cost has been roughly estimated at about 25-30 billion euro; the time span of construction activities could be of about 20 years, so that the yearly allocations needed would be of the same order of magnitude of the damage costs incurred each year as a consequence of extreme hydro-geological hazards. The economic estimate is in accordance with the construction of large water projects costs such as the Three Gorges Dam in China (around 30 billion euro), GMRP in Lybia (around 25 billion euro), water transfer system from South to North of China (around 8 billion euro). Considering the presence on the Italian territory of more than 540 large dams (Figure 10 ) and thousands of smaller reservoirs, it would be advisable to try and include some of them in the scheme here presented, reducing the total cost of the project. Possible differences in the elevations chosen to build the reservoirs - as a consequence of the geological situation and keeping duly into account the anthropization of the valleys where the dams should have to be located - could be compensated by the construction of pumping systems whose number and characteristics should be evaluated in the frame of a feasibility study. Such a large system, accepting irregular inflows and accommodating variable demands of utilisation, would operate practically all the time under conditions of transient hydraulic regime. A numerical model of the interconnection was set up and run through a series of simulations, under a spectrum of different assumptions about flood inflows occurring at certain points or peaks of demand concentrated at given sections.
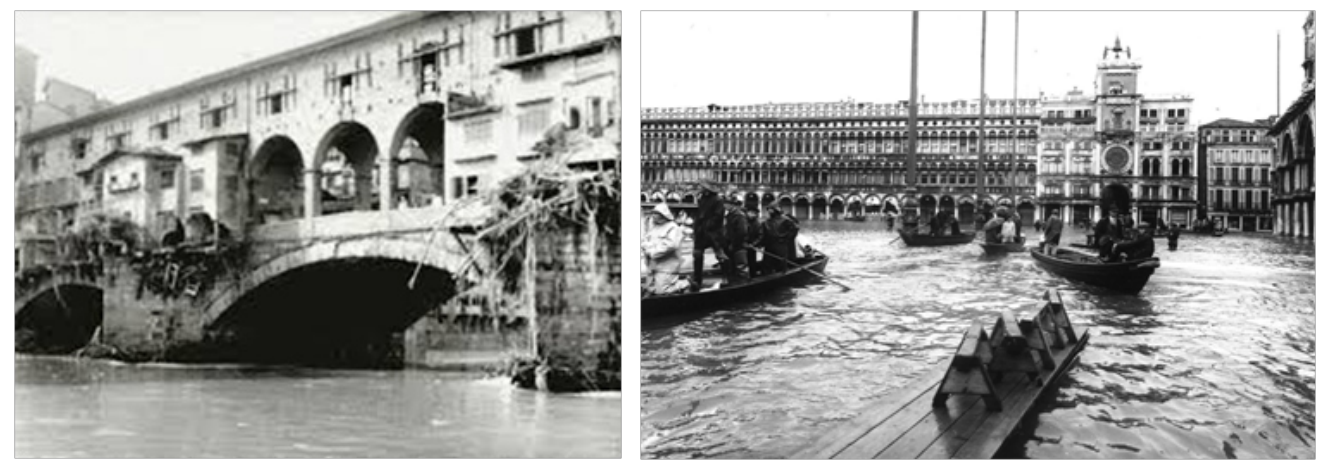

Figure 7 The disastrous floods of Florence (left) and Venice (right) of November 1966 in Italy.

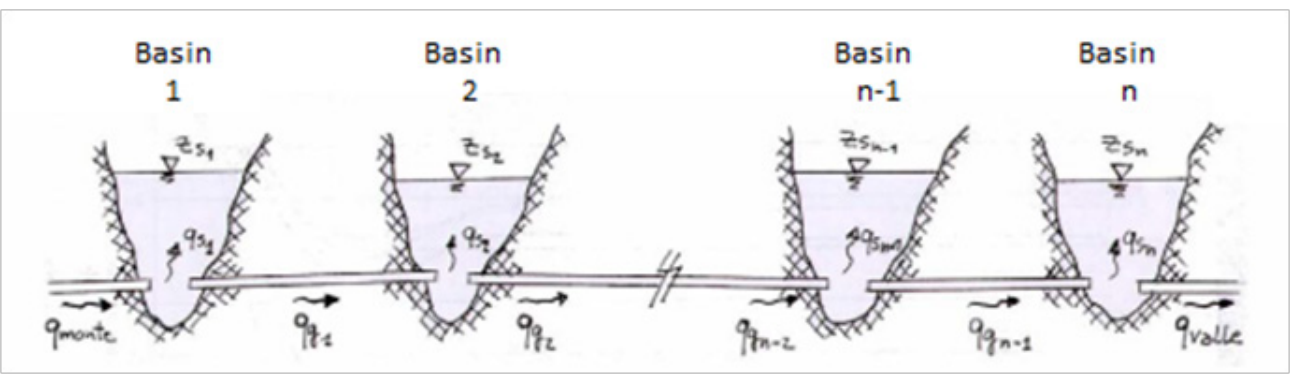

Figure 8 Simplified scheme of the interconnected reservoirs.

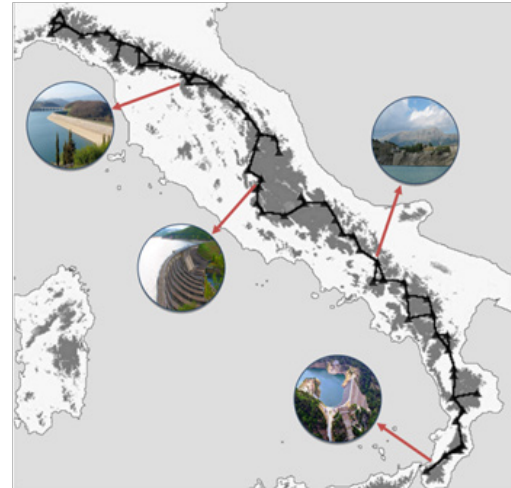

Figure 9 Italian long-range hydraulic interconnection scheme along the Apennines Mountains.

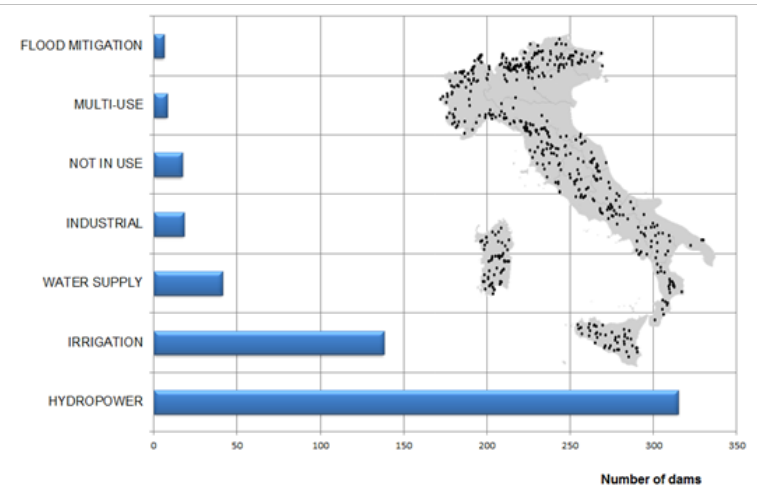

Figure 10 Number and distribution of Italian dams subdivided according to their main purpose. 


\section{Final remarks}

The conclusion of this investigation was that the transit times of the 'signal' of a perturbation from one end of the system to the other end is of the order of two-three days, while the time needed to reach a steady-state condition is of the order of several days. However, the maximum differences in the water levels occurring among the many reservoirs during such transients would remain limited to very few metres; the clearances between operating maximum levels and spillways crest would have, of course, to be fixed keeping into account these results. Of course a less ambitious solution could be considered limiting the design of such a system to a regional or macro-regional scale. While the technical and economic feasibility of this kind of infrastructure does not appear out of the realm of presentday possibilities, the greatest uncertainty rests with the socio-political acceptability of such an ambitious program, which would enter in competition with other perceived priorities.

\section{Acknowledgements}

The Authors wish to express their thankfulness to Giorgio BOLDINI, President of the National Hanging Gardens Association, who is giving great support to the promotion of the study described in the present paper. This work has been financed by the Research Fund for the Italian Electrical System under the Contract Agreement between RSE S.p.A. and the Ministry of Economic Development General Directorate for Nuclear Energy, Renewable Energy and Energy Efficiency in compliance with the Decree of March 8, 2006.

\section{Conflict of interest}

Authors declare there is no conflict of interest in publishing the article.

\section{References}

1. Zambas, Faisal KZ, Azriel y, et al. Underground Aqueducts Handbook. In: Angelakis et al. (Eds.), The aqueduct of Eupalinos on Samos, Greece and its restoration, CRC Press, USA; 2017. p. 1-17.
2. De Feo G, Angelakis AN, Antoniou GP, et al. Historical and Technical Notes on Aqueducts from Prehistoric to Medieval Times. Water 2013;5(4):1996-2025.

3. Voudouris K, Christodoulakos Y, Stiakakis M, et al. Hydrogeological Characteristics of Hellenic Aqueducts-like Qanats. Water. 2013;5(3):1326-1345.

4. Haut B, Zheng XY, Mays L, et al. Water and Heritage: Material, Conceptual, and Spiritual connections. In: Willems WJH \& Schaik HPJV, editors. Evolution of rainwater harvesting and heritage in urban areas through the millennia: A sustainable technology for increasing water availability. Sidestone Press, Netherlands; 2015. p. 37-56.

5. Angelakis AN, Chiotis E, Eslamian S, et al. Underground Aqueducts Handbook. CRC Press, USA; 2016. p. 1-522.

6. Ricercadi Sistema. Studio di pre-fattibilità di una interconnessione idrica tra nord e sud Italia mirante alla protezione idrogeologica ed alla mitigazione delle siccità: Sviluppo dell'indagine. Italian Ministry of Economic Development. Italy; 2004.

7. Fanelli M, Mazzà G, Cadei R. The long-range hydraulic interconnections: a dawning possibility. XXII ICOLD Congress, Spain; 2016.

8. European ICOLD Club. European Working Group on Dams and Floods. Dams and Floods in Europe. Role of Dams in Flood Mitigation. Spain; 2010 .

9. De Marchi G. Commissione Interministeriale per lo studio della gestione idraulica e la difesa del territorio in Italia. Rapporto conclusivo. Italy; 1970.

10. ICID. Compilation of International Experiences in Inter-Basin Water Transfer. International Commission on Irrigation and Drainage India; 2003. 